\title{
ANFIS Based DTC SVPWM Controller for Induction Motor
}

\author{
Rohit Kumar ${ }^{1}$ | Dr. B. Amarendra Reddy ${ }^{2}$ \\ ${ }^{1}$ PG Student, Dept of EEE, Andhra University College of Engineering, Vizag \\ ${ }^{2}$ Assistant Professor, Dept of EEE, Andhra University College of Engineering, Vizag
}

To Cite this Article

Rohit Kumar and Dr. B. Amarendra Reddy, "ANFIS Based DTC SVPWM Controller for Induction Motor", International Journal for Modern Trends in Science and Technology, 6(11): 06-11, 2020.

\section{Article Info}

Received on 06-October-2020, Revised on 18-October-2020, Accepted on 25-October-2020, Published on 30-October-2020.

\section{ABSTRACT}

This paper presents three PWM techniques, space vector PWM (SVPWM). SVPWM gives the more rms stator flux ripples in induction motor at 0.76 modulation indices, which gives more ripples in current and torque distortion. The flux performance of the induction motor is improved using three PWM (TPWM) due to twin switching transition with less area of rms stator flux ripple. The PI-control (PIC) doesn't give the good dynamic performance of the induction motor drive using two level Voltage Source Inverter due to sudden changes in the load or speed. Further to improve dynamic performance in the torque and Flux of induction motor drive is simulated using type-2 fuzzy logic control (TP2FLC) and ANN in place of PIC because; TP2FLC and ANN is effectively dealing with uncertainties, and simulation results of speed, torque, flux and stator current of induction motor is compare with PIC of SVPWM and TPWM.

Keywords: Space Vector PWM, Type2 Fuzzy logic Control, ANN Control, Two level Voltage Source Inverter and Scalar Control of Induction Motor.

\section{INTRODUCTION}

In 1882, Nikola Tesla identified the rotating magnetic field principle, and pioneered the use of a rotary field of force to operate machines. He exploited the principle to design a unique two-phase induction motor in 1883. An induction motor (IM) is a type of asynchronous AC motor where power is supplied to the rotating device by means of electromagnetic induction. Other commonly used name is squirrel cage motor due to the fact that the rotor bars with short circuit rings resemble a squirrel cage (hamster wheel).An electric motor convert's electrical power to mechanical power in its rotor.

Induction motor (IM) can be considered as the 'workhorse' of the industry because of its special features such as low cost, high reliability, low inertia, simplicity and ruggedness. Even today IMs especially the squirrel cage type, are widely used for single speed applications rather than variable speed applications due to the complexity of controlling algorithm and higher production cost of IM variable speed drives. However, there is a great interest on variable speed operation of IM within the research community mainly because IMs can be considered as a major industrial load of a power system. On the other hand the IMs consume a considerable amount of electricity generated. The majority of IMs are operated at constant speed, determined by the pole pair number and the stator supply frequency.

There are many senseless methods. Which, class to two kinds, open loop and closed loop. Up to this moment, there are many open loop sensorless 
schemes have been presented bur all of them have many defected by motor parameters like stator currents and stator voltage. But the closed loop method gets very low defected by motor parameters and feedback variable because calculate and estimate process always have feedback to adjust transition error. So, this closed loop control method is manage to estimate rotor speed by two models i.e one is reference model and another one is adaptive model, which is also used to estimate rotor flux and the error of 2 those signals have been adjusted through PI control unit. In this, the paper also concerning about stator resistance estimate method. It gives the result that estimate of rotor speed do not effect by stator resistance.

The basic characteristic of DTC is that the positions of the inverter switches are directly determined rather than indirectly, thus refraining from using a modulation technique like Pulse Width (PWM) or Space Vector (SVM) modulation. In the generic scheme, the control objective is to keep the motor's torque and the amplitude of the stator flux within pre-specified bounds. The inverter is triggered by hysteresis controllers to switch whenever these bounds are violated.

In general, the two-level inverter-fed IM drives are suitable for low-voltage applications, but not medium voltage. Because, the two-level inverter has few limitations such as high switching frequency, more voltage/current stresses on devices, switching losses, and overall cost of the inverter. To overcome the above drawbacks, the multilevel inverter is used for medium-voltage applications. The CDTC along with three-level diode-clamped inverter reduces the torque and flux distortion of the IM drive than the two-level inverter. The fuzzy-1 DTC along with the TDCI improves the dynamic performance of the IM than conventional TDCI. The Artificial Neural Network is used in this paper to further improve the dynamic response of the IM drive using three-level SVPWM than the conventional control scheme.

\section{DESIGNING OF INDUCTION MOTOR:}

An induction motor (IM) is a type of asynchronous AC motor where power is supplied to the rotating device by means of electromagnetic induction. Other commonly used name is squirrel cage motor due to the fact that the rotor bars with short circuit rings resemble a squirrel cage (hamster wheel).An electric motor convert's electrical power to mechanical power in its rotor.

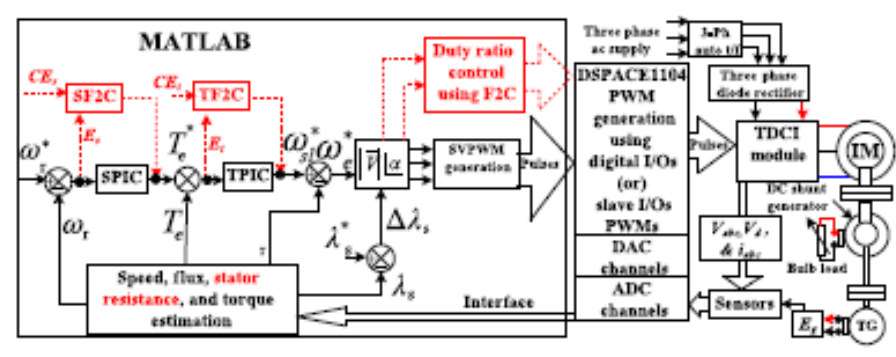

Figure 1: The equivalent representation of a three phase two-level inverter driving an induction motor

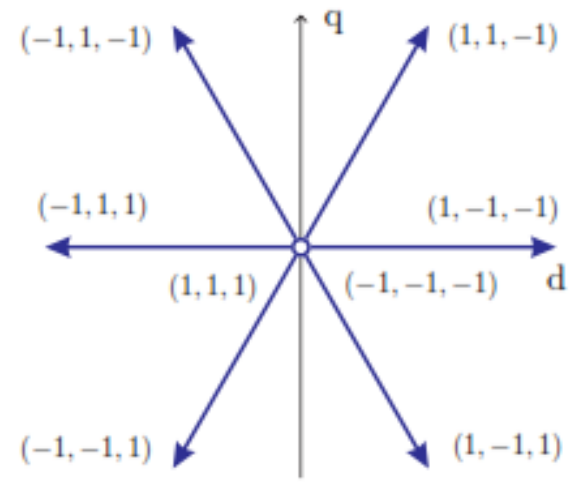

Figure 2: The voltage vectors on the dq plane with switch positions

The ac induction motor is by far the most widely used motor in the industry. Traditionally, it has been used in constant and variable-speed drive applications that do not cater for fast dynamic processes. Because of the recent development of several new control technologies [5], such as vector and direct torque controls, this situation is changing rapidly. The underlying reason for this is the fact that the cage induction motor is much cheaper and more rugged than its competitor, the dc motor, in such applications. This section starts with induction motor drives that are based on the steady-state equivalent circuit of the motor, followed by vector-controlled drives that are based on its dynamic model as shown in the above figures $1 \& 2$.

\section{Mathematical Model of Induction Motor:}

When describing a three-phase IM by a system of equations the following simplifying assumptions are made:

- The three-phase motor is symmetrical,

- Only the fundamental harmonic is considered, while the higher harmonics of the spatial field distribution and of the magneto motive force (MMF) in the air gap are disregarded,

- The spatially distributed stator and rotor windings are replaced by a specially formed, so-called concentrated coil, 
- The effects of anisotropy, magnetic saturation, iron losses and eddy currents are neglected,

- The coil resistances and reactance are taken to be constant,

- In many cases, especially when considering steady state, the current and voltages are taken to be sinusoidal.

Taking into consideration the above stated assumptions the following equations of the instantaneous stator phase voltage values can be written:

Vqss $=$ Rs iqss + d $\psi q s s / d t$

Vdss $=$ Rs idss + d $\psi d s s / d t$

The development of torque by the interaction of air gap flux and rotor mmf was discussed earlier in this chapter. Hence it will be expressed in more general form, relating the d-q components [6] of variables. From equation

$\mathrm{Te}=(3 / 2)(\mathrm{p} / 2) \psi^{\wedge} \operatorname{mIrsin} \delta$,

the torque can be generally expressed in the vector form as

$\mathrm{Te}=(3 / 2)(\mathrm{p} / 2)(\psi \mathrm{dIq}-\psi \mathrm{qId})$

\section{Direct Torque Control (DTC):}

Direct Torque Control (DTC) is a method that has emerged to become one possible alternative to the well-known Vector Control of Induction Motors. This method provides a good performance with a simpler structure and control diagram. In DTC it is possible to control directly the stator flux and the torque by selecting the appropriate VSI state. A variety of techniques have been proposed to overcome some of the drawbacks present in DTC $[2,8]$. Some solutions proposed are: DTC with Space Vector Modulation (SVM); the use of a duty--ratio controller to introduce a modulation between active vectors chosen from the look-up table and the zero vectors; use of artificial intelligence techniques. A different approach to improve DTC features is to employ different converter topologies from the standard two-level VSI. The major advantage of the three-level VSI topology when applied to DTC is the increase in the number of voltage vectors available. This means the number of possibilities in the vector selection process is greatly increased and may lead to a more accurate control system, which may result in a reduction in the torque and flux ripples.
In principle the DTC method selects one of the six nonzero and two zero voltage vectors of the inverter on the basis of the instantaneous errors in torque and stator flux magnitude. The block diagram of classical DTC proposed by I. Takahashi and T. Nogouchi is presented in Fig.

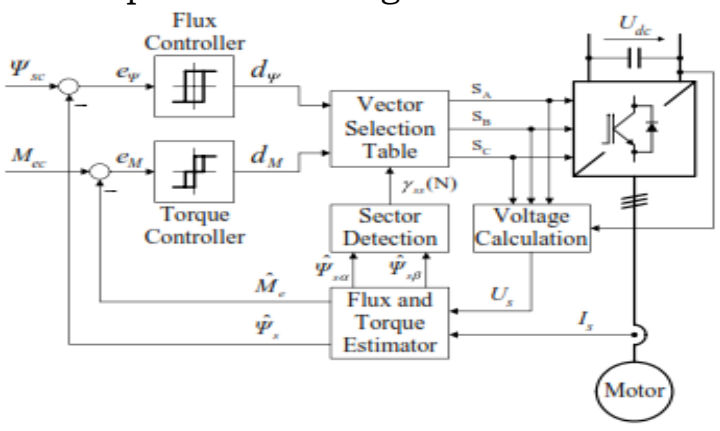

Figure 3: DTC control scheme

\section{Space Vector PWM:}

The Space Vector PWM generation module accepts modulation index commands and generates the appropriate gate drive waveforms for each PWM cycle. This section describes the operation and configuration of the SVPWM module [7].

A three-phase 2-level inverter with dc link configuration can have eight possible switching states, which generates output voltage of the inverter. Each inverter switching state generates a voltage Space Vector (V1 to V6 active vectors, V7 and V8 zero voltage vectors) in the Space Vector plane (Figure: space vector diagram). The magnitude of each active vector (V1to V6) is $2 / 3$ Vdc (dc bus voltage).

The Space Vector PWM (SVPWM) module inputs modulation index commands (U_Alpha and U_Beta) which are orthogonal signals (Alpha and Beta) as shown in Figure. The gain characteristic of the SVPWM module is given in Figure. The vertical axis of Figure represents the normalized peak motor phase voltage $(\mathrm{V} / \mathrm{Vdc})$ and the horizontal axis represents the normalized modulation index (M).

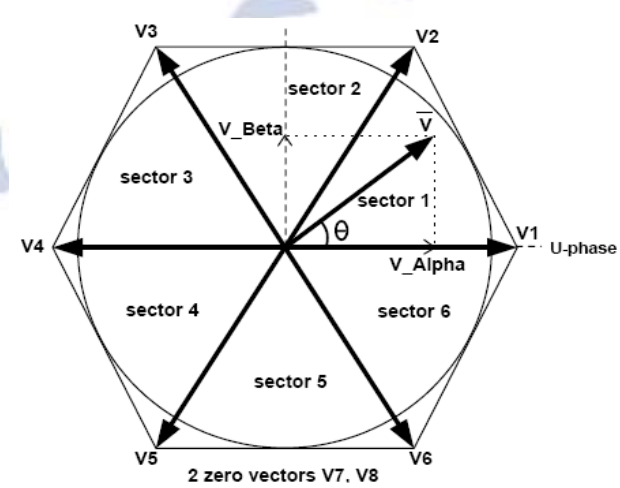

Figure 4: Space Vector Diagram 
The inverter fundamental line-to-line Rms output voltage (Vline) can be approximated (linear range) by the following equation:

$$
\text { Vline }=\text { Umag* Mod_Scl* } V d c / \sqrt{6} / 2^{25}
$$

\section{CONTROLLER DESIGN: \\ PI Controller:}

PI control With a view to have a self-regulated speed, the speed of induction is sensed and controlled by employing a suitable closed loop control. The speed of IM is sensed at a regular interval and is compared with its reference counterpart $\mathrm{N}^{*}$. The error signal is processed in a PI controller.

\section{Fuzzy Logic Controller}

In the previous section, control strategy based on PI controller is discussed. But in case of PI controller, it has high settling time and has large steady state error. In order to rectify this problem, this paper proposes the application of a fuzzy controller shown in Figure. Generally, the FLC is one of the most important software based technique in adaptive methods.

As compared with previous controllers, the FLC has low settling time, low steady state errors. The operation of fuzzy controller can be explained in four steps.

1. Fuzzification

2. Membership function

3. Rule-base formation

4. Defuzzification.

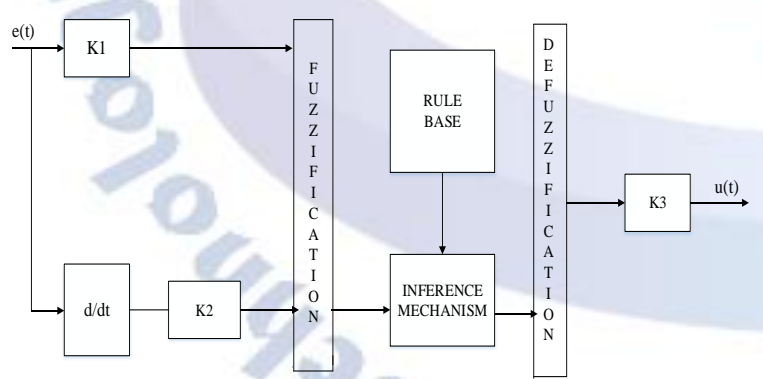

Figure 5: basic structure of fuzzy logic controller

In this paper, the membership function is considered as a type in triangular membership function and method for defuzzification is considered as centroid. The error which is obtained from the comparison of reference and actual values is given to fuzzy inference engine. The input variables such as error and error rate are expressed in terms of fuzzy set with the linguistic terms VN, N, Z, P, and Pin this type of mamdani fuzzy inference system the linguistic terms are expressed using triangular membership functions.
In this paper, single input and single output fuzzy inference system is considered.

\section{Artificial Neural Networks}

Figure 6 shows the basic architecture of artificial neural network, in which a hidden layer is indicated by circle, an adaptive node is represented by square. In this structure hidden layers are presented in between input and output layer, these nodes are functioning as membership functions and the rules obtained based on the if-then statements is eliminated. For simplicity, we considering the examined ANN have two inputs and one output. In this network, each neuron and each element of the input vector $\mathrm{p}$ are connected with weight matrix $\mathrm{W}$.

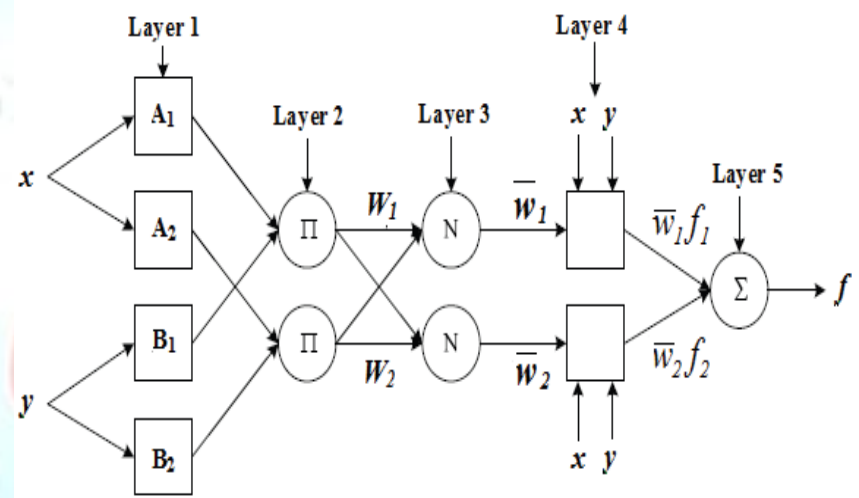

Figure 6: ANN architecture for a two-input multi-layer network

Where the two crisp inputs are $\mathrm{x}$ and $\mathrm{y}$, the linguistic variables associated with the node function are $\mathrm{Ai}$ and $\mathrm{Bi}$.

\section{SIMULATION RESULT:}

The induction motor is simulated using Scalar control for two level SVPWM with $3 \mathrm{kHz}$ switching frequency, and reference speed $1400 \mathrm{rpm}$ is applied to VSI inverter fed induction motor drive. PI-control is replaced by TP2FLC of Scalar control induction motor drive using three PWM; the reference speed is same as above as shown in Figure 7 . The torque, flux and speed can reach very quickly with less distortion in flux and torque even the speed variation takes place. So the transient and steady state performance of torque flux and speed of induction motor has been improved using type- 2 fuzzy logic and ANN controllers. The reason is mainly due to the TP2FLC can estimate the control output or centroide, which is very near to the required value but the PI-control didn't give the good performance especially at speed changing condition and non-linear system. 


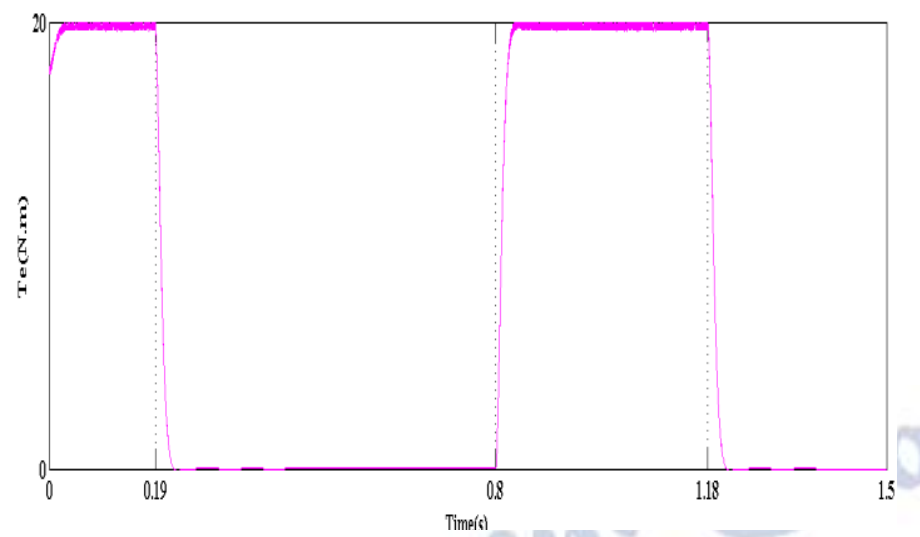

Figure 7: Torque Waveform of PIDTC of IM Using Three level Inverter at Starting

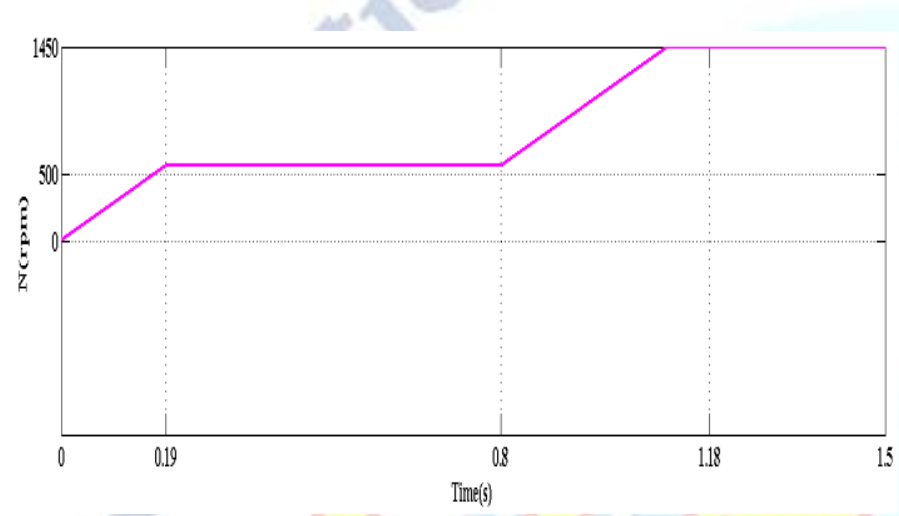

Figure 8: Speed Waveform of PIDTC of IM Using Three level Inverter at Starting

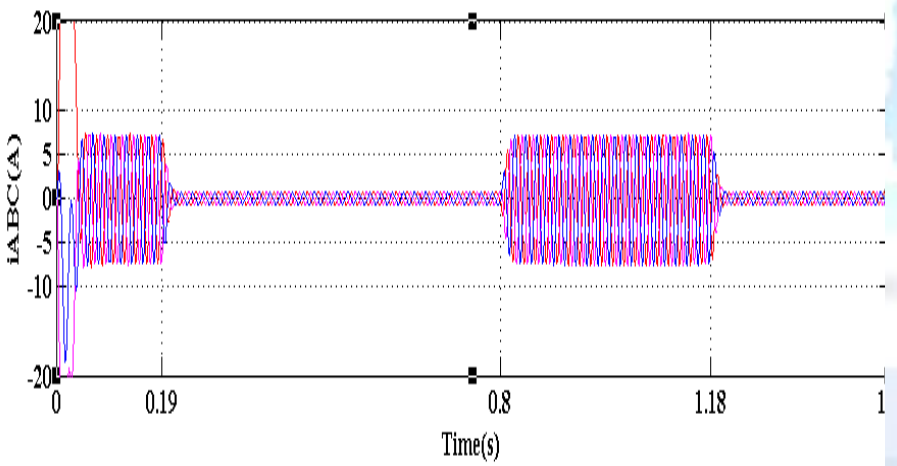

Figure 9: Current Waveform of PIDTC of IM Using Three level Inverter at Starting

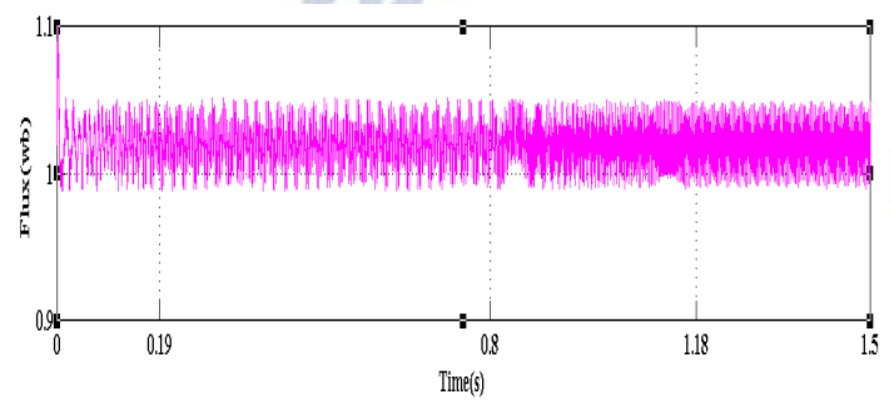

Figure 10: Flux Waveform of PIDTC of IM Using Three level Inverter at Starting

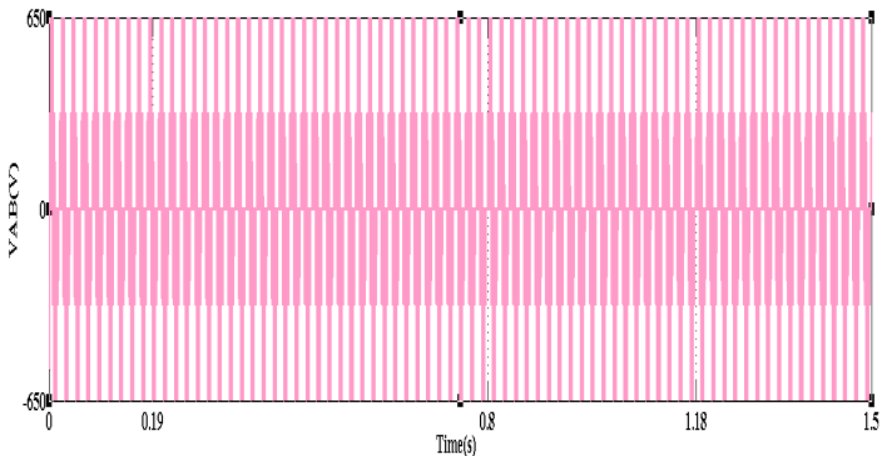

Figure 11: Voltage Waveform of PIDTC of IM Using Three level Inverter at Starting

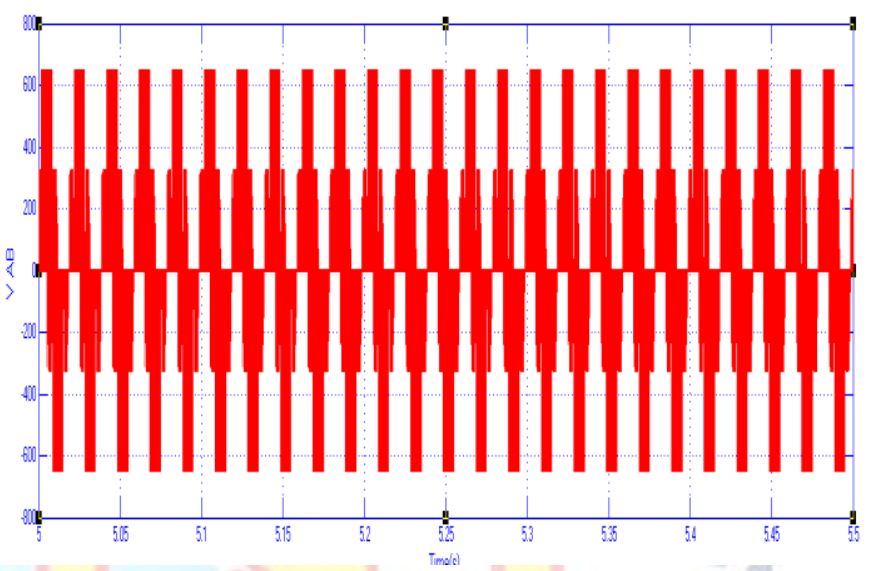

Figure 12: Voltage waveform of F2DTC of IM Using Three level Inverter at Starting

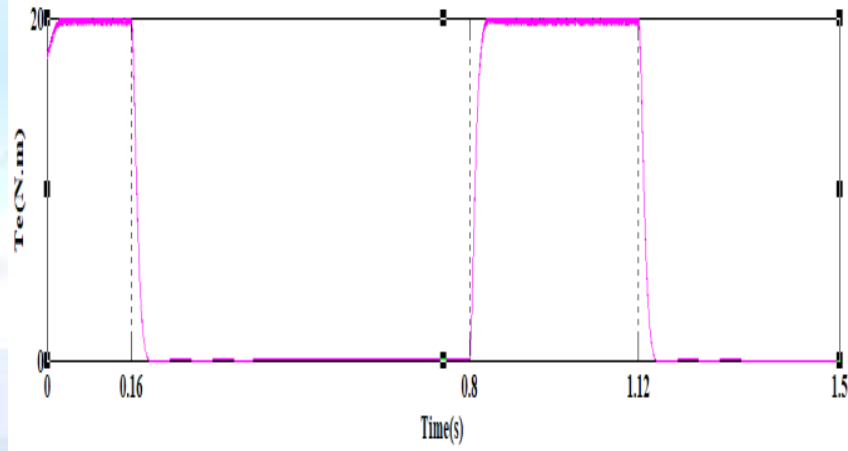

Figure 13: Torque Waveform of F2DTC of IM Using Three level Inverter at Starting

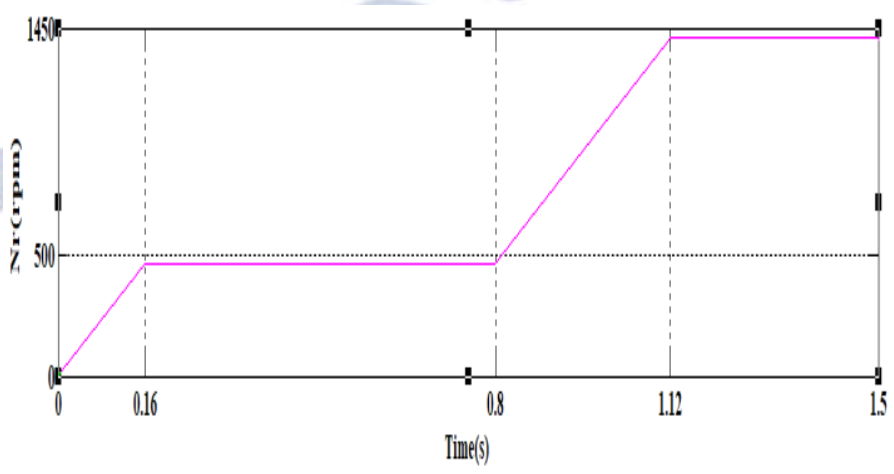

Figure 14: Speed Waveform of F2DTC of IM Using Three level Inverter at Starting 


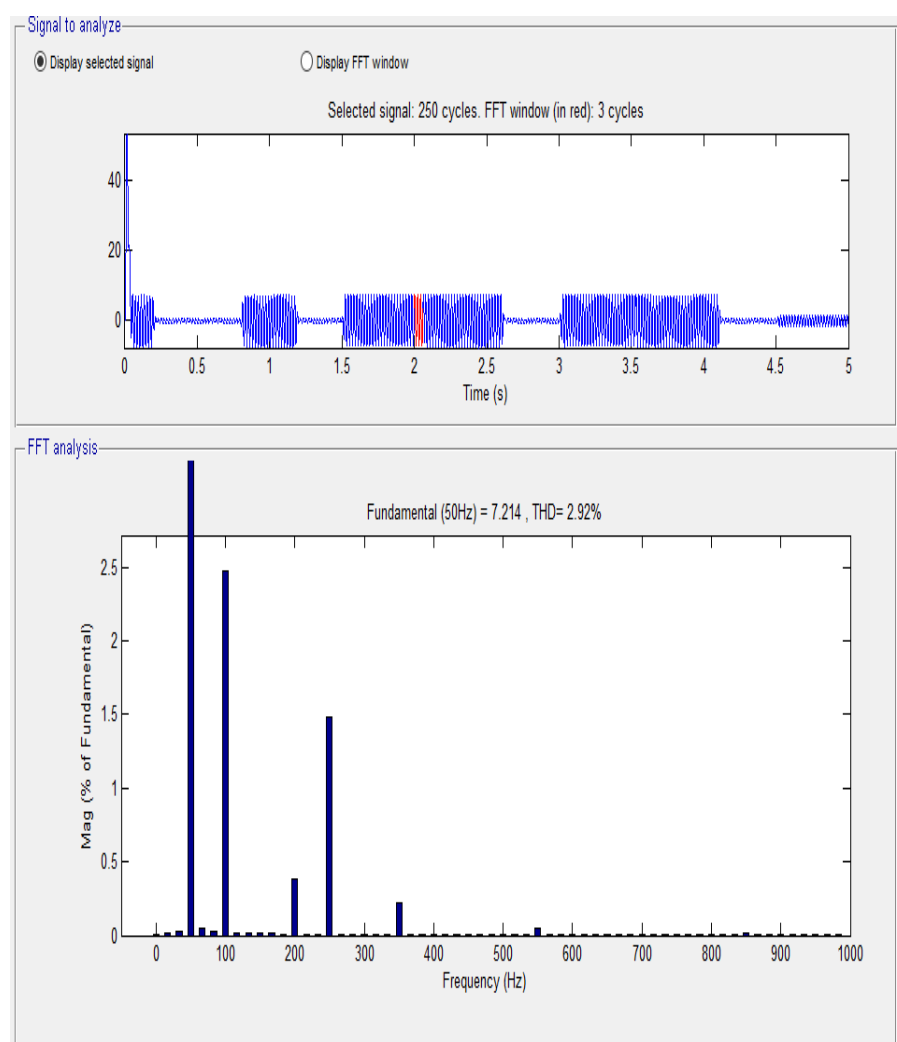

Figure 15: Stator Current THD of IM with F2DTC

\section{CONCLUSION:}

The results of the induction motor for two level voltage source inverter are developed using SVPWM, and the speed of induction motor is controlled using Scalar control technique. The TPWM is given lower current ripple, less flux and torque distortion as compared to SVPWM. In order to improve the current, torque and flux performance of induction motor drive, the Type- 2 fuzzy logic and ANN controllers is placed on PI-Control using TPWM. The Type-2 FLC and ANN controllers based TPWM gives an excellent dynamic performance on torque and flux distortion of the induction motor with less current THD than PIC of TPWM.

\section{REFERENCES}

[1] Alexis Kwasinski, Philip T. Krein, and Patrick L. Chapman, "Time Domain Comparison of Pulse-Width Modulation Schemes", IEEE Trans on Power Electron. vol. 1, no. 3, pp. 64-68, Sept 2003.

[2] G. Narayanan, Di Zhao, Harish and K. Krishnamurthy, "Space Vector Based Hybrid PWM Techniques for Reduced Current Ripple," IEEE Trans. on Ind. Electron, vol. 55, no. 4, pp. 1614-1627, April 2008.

[3] G. Narayanan, H. K. Krishnamurthy, D. Zhao, and R. Ayyanar, "Advanced bus-clamping PWM techniques based on space vector approach," IEEE Trans. Power Electron., vol. 21, no. 4, pp. 974-984, Jul. 2006.

[4] Gilberto C.D. Sousa, and Bimal K. Bose, "A fuzzy set theory based control of a phase-controlled converter dc machine drive“, IEEE Trans. Industry Applications, Vol. 30, No. 1, pp. 34-43, 1994.

[5] S. Yuvarajan, Abdollah Khoei and Kh. Hadidi, "Fuzzy logic DC motor controller with improved performance", IEEE Trans. Power Electronics, vol. 11, no.3, pp 1652-1656, 1998.

[6] Bimal. K. Bose, "Modern Power Electronics and Ac Drives," Prentice Hall PTR, 2002 [book]

[7] P.C.Krause, Oleg Wasynczuk and Scott D.Sudhoff "Analysis of Electrical Machinery and Drive systems," Second Edition-IEEE Press[book].

[8] N. N. Karnik, J. M. Mendel, and Q. Liang, "Type-2 fuzzy logic systems," IEEE Trans Fuzzy Syst vol. 7 pp. 643-658, Sept 1999.

[9] J. M. Mendel and R. I. B. John, "Type-2 fuzzy sets made simple," IEEE Trans on Fuzzy System, vol.10, pp.117-127, 2002.

[10] Q. Liang and J. M. Mendel, "Interval type-2 fuzzy logic systems: Theory and design," IEEE Trans on Fuzzy System, vol. 8, pp. 535-550, 2000.

[11] Q. Liang, N. N. Karnik, and J. M. Mendel, "Connection admission control in ATM networks using surveybased type-2 fuzzy logic systems," IEEE Trans on Syst Man Cybern Part C, vol. 30, pp.329-339. 2000.

[12] J. M. Mendel, Uncertain rule-based fuzzy logic systems: Introduction and new directions. Prentice Hall PTR, Upper Saddle River, NJ, 2001.

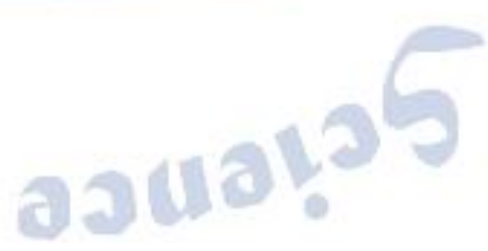

